\title{
Reconciling Neg-Raising and NPIs in Korean
}

Lyn Shan Tieu (lyn.tieu@uconn. edu) \& Jungmin Kang (jung-min.kang@uconn. edu)

\author{
University of Connecticut
}

\section{The Puzzle}

In neg-raising constructions, the matrix negation can be interpreted as if in the embedded clause. For example, the neg-raising construction in (1a) seems to strongly implicate the reading in (1b), despite the appearance of negation in the matrix clause.

(1) a. John doesn't believe Mary left

--implies-->

b. John believes Mary didn't leave

Korean also appears to exhibit an equivalent kind of neg-raising construction, as seen in (2). As in the English (1), the negation in the matrix clause can be interpreted as if in the embedded clause, resulting in the interpretation in (2b).

a. [John-un [Mary-ka ttenassta-ko] mit-ci anh-nunta]

John-TOP Mary-NOM left-COMP believe-CI NEG-PRES.DECL

'John doesn't believe that Mary left'

--implies-->

b. John-un Mary-ka ttena-ci an-hassta-ko mitnunta

John-TOP Mary-NOM leave-CI NEG-did-COMP believe

'John believes that Mary didn't leave'

In English, the negation in the matrix clause of the neg-raising construction can license an NPI in the embedded clause, as seen in (3).

(3) Mary didn't believe that John bought anything.

In fact, long-distance licensing of strict NPIs is often taken to be diagnostic of neg-raising (Lakoff, 1969; Horn, 1978; Gajewski 2007, a.o.). Given that Korean appears to exhibit neg-raising as in (2), we might expect the negation in the Korean neg-raising construction to similarly license strict NPIs (such as ати-(N)-to 'any-N'). As observed by Bošković (2008) however, strict NPI licensing in neg-raising constructions is not possible in Korean. In (4), the negation in the matrix clause fails to license the NPI amukes-to in the embedded clause, resulting in the ungrammaticality of the sentence.

$$
\begin{aligned}
& \text { *[Mary-ka [John-i amukes-to saestta-ko] mit-ci ani hayessta] } \\
& \text { Mary-NOM John-NOM anything-even bought-COMP believe-CI not did } \\
& \text { 'Mary didn't believe that John bought anything' }
\end{aligned}
$$

Bošković and Gajewski (2011) report that Korean does not have neg-raising, and thus cannot exhibit such strict NPI licensing. Their claim is made in the context of Bošković's (2008) 
observation that languages without articles disallow neg-raising, while those with articles allow it. ${ }^{1}$ According to these authors, (2) might be derived pragmatically. We suggest instead that both English and Korean exhibit neg-raising, and argue that the discrepancy in whether the respective neg-raising constructions can license strict NPIs falls out not from whether the language has articles, but whether the NPIs in the relevant language contain an even-like particle. ${ }^{2}$

\section{The Proposal}

\subsection{Neg-raising \& NPI Licensing (Gajewski, 2007)}

Consider first the basic facts about neg-raising and NPI licensing. Neg-raising predicates (NRPs) introduce a set of alternatives that includes their internal negation:

a believes $p \vee$ a believes $\sim p$

NRPs trigger an excluded middle (EM) presupposition that projects through negation. The assertion and presupposition reduce to the second disjunct of the presupposition, giving rise to the implication in (1).

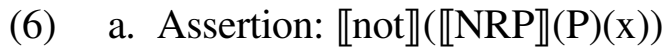

John doesn't believe Mary left.

b. Presupposition: $\mathrm{M}(\mathrm{x}) \subseteq \mathrm{P}$ or $\mathrm{M}(\mathrm{x}) \cap \mathrm{P}=\varnothing$

John believes Mary left or John believes Mary didn't leave.

c. Truth condition: $\mathrm{M}(\mathrm{x}) \nsubseteq \mathrm{P}$

John believes Mary didn't leave.

(Gajewski, 2007:304)

Negated NRPs license strong NPIs. Zwarts (1998) proposed that there are three classes of NPIs (79), licensed accordingly by three classes of licensers that differ by "negative strength", i.e. by the number of De Morgan's laws that they validate (10). While weak NPIs require licensing by merely downward-entailing operators, strong NPIs require anti-additive licensers, and superstrong NPIs require licensing by anti-morphic operators.

(7) Weak NPIs: any, ever

(8) Strong NPIs: either, until, in weeks/months/years, minimizers

(9) Superstrong NPIs: one bit, a bit
(i) $\quad f(x) \vee f(y) \rightarrow f(x \wedge y)$
(ii) $\mathrm{f}(\mathrm{x} \vee \mathrm{y}) \rightarrow \mathrm{f}(\mathrm{x}) \wedge \mathrm{f}(\mathrm{y})$
(iii) $\mathrm{f}(\mathrm{x}) \wedge \mathrm{f}(\mathrm{y}) \rightarrow \mathrm{f}(\mathrm{x} \vee \mathrm{y})$
(iv) $\mathrm{f}(\mathrm{x} \wedge \mathrm{y}) \rightarrow \mathrm{f}(\mathrm{x}) \vee \mathrm{f}(\mathrm{y})$
Downward-entailing (license weak NPIs) Anti-additive (license strong NPIs) Anti-morphic (license superstrong NPIs)

\footnotetext{
Based on similarities in the interpretation of definite plurals and neg-raising predicates, Bošković and Gajewski (2011) argue that a language can have neg-raising only if it has a definite article with which to construct a world-sum denoting predicate (see their paper for details). The lack of a definite article in article-less languages thus results in the lack of neg-raising predicates in such languages.

2 We are not ruling out the possibility that there may nevertheless be certain interactions between the negraising/NPI facts and the article/article-less distinction (cf. Bošković, 2010).
} 
Gajewski (2007) shows that negated NRPs support anti-additive inferences, such as that in (11), and thus not surprisingly license strong NPIs, as seen in (12).

(11) John doesn't think Mary arrived and John doesn't think Bill arrived $\Rightarrow$ John doesn't think Mary arrived or Bill arrived

(12) John doesn't believe Mary arrived until yesterday.

Our goal is to reconcile the NRP and NPI facts by appealing to the presuppositions of strict NPIs in Korean.

\subsection{NPIs in Korean}

Turning now to Korean, An (2007) argues that amu-(N)-to NPIs contain (i) the indefinite amu, corresponding to the cardinality predicate one, and (ii) the even-like emphatic particle to. According to An, the even-like particle to triggers a scalar presupposition. For example, the sentence in (13) asserts (14a) and presupposes (14b); additionally, it triggers the scalar presupposition in (15).

(13) John-to wa-ss-ta John-even come- PAST.DECL

'John also came'

(14) a. John came.

b. $\exists x[\mathrm{x} \neq \mathrm{John} \wedge \mathrm{x}$ came $]$

$\forall \mathrm{x}[\mathrm{x} \neq \mathrm{John} \rightarrow \operatorname{likelihood}(\mathrm{x}$ came $)>\operatorname{likelihood}($ John came $)]$

Moreover, based on the distribution of NPIs in Korean, An argues that to must scope above negation, but crucially cannot scope outside of its minimal clause (see An, 2007 for details). With to scoping over negation, (16) correctly presupposes that 'John didn't read one book' is the least likely proposition among the alternatives (it is more likely that he read one book than that he read $n>1$ books). Thus the configuration in (17a) leads to a presupposition clash.

(16) John-un amu-chayk-to ilk-ci ahn-assta

John-TOP any-book-even read-CI not-PAST.DECL

'John did not read any books'

(An, 2007:322)

(17) a. \#[ NEG [ to [ John read one book ]]]

b. [ to [ NEG [ John read one book ]]]

\subsection{Presupposition Failure}

Returning to the ungrammaticality of (4), repeated below as (18), we propose that the even-like presupposition of to is incompatible with the EM presupposition triggered by negated NRPs.

$\begin{array}{llllll}\text { *Mary-ka John-i } & \text { amukes-to saestta-ko } & \text { mit-ci } & \text { ani hayessta } \\ \text { Mary-NOM John-NOM } & \text { anything-even bought-COMP } & \text { believe-CI not did } \\ \text { 'Mary didn't believe that John bought anything.' } & & \end{array}$


Recall that to cannot scope outside of its minimal clause (An, 2007); assuming a semantic account of NPRs (such as the one put forth by Gajewski, 2007), it follows that to cannot scope over negation in NRPs. The resulting presupposition - that 'John bought one thing' is the least likely alternative - conflicts with the general notion of likelihood whereby the weakest value should be the most likely (being entailed by all other alternatives). Neither disjunct of the NRP presupposition can be true, so the sentence as a whole suffers from presupposition failure.

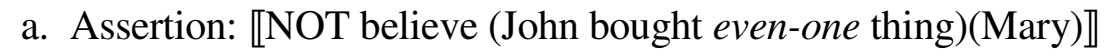
Mary didn't believe John bought even-one thing

b. Presupposition: $\mathrm{M}(\mathrm{x}) \subseteq \mathrm{P}$ or $\mathrm{M}(\mathrm{x}) \cap \mathrm{P}=\varnothing$ Mary believed John bought even-one thing or Mary believed John didn't buy even-one thing

c. Truth condition: \#

The presuppositions of the strict NPIs in question thus allow us to preserve a unified account of NRPs, while explaining the apparent divergence in NPI licensing.

\section{Future Directions}

We have suggested that whether a language exhibits NPI licensing in neg-raising constructions falls out from a particular property of the NPIs of that language, namely whether the NPI is composed in part of an even-like particle. We have suggested that Korean, in which NPIs come with the particle to, does not exhibit NPI licensing in neg-raising constructions because of a conflict between the presupposition of the neg-raising construction and the scalar presupposition that is induced by the particle to. Two issues are currently under investigation. First, under the proposed account, what matters for NPI licensing in NRPs is whether the NPI in the given language contains an even-like particle. We thus predict that if the NPIs of a certain language come with an even-like component (e.g., Hindi, cf. Lahiri, 1998), we should not find strict NPI licensing in the NRPs of that language. We are currently investigating this prediction cross-linguistically. A second task involves establishing the scope facts of even-like particles across languages. Recall An's requirement that Korean to cannot scope outside of its minimal clause, for example; it is this apparent clause-boundedness of to that leads to presupposition failure in NRPs, under our proposal. This clause-boundedness might be a general fact about the emphatic particle to, independently of whether it is attached to NPIs. Languages might behave differently with respect to the properties of their emphatic particles. One might thus expect to see different patterns arising from interactions involving even-like particles, the scope restrictions of these particles in different languages, and the presuppositions that arise when NPIs containing such emphatic particles are found in the negraising constructions of these languages. We are thus also presently exploring these interactions cross-linguistically.

\section{References}

An, Duk-Ho. 2007. "On the distribution of NPIs in Korean.” Natural Language Semantics 15:317-350. Bošković, Željko. 2008. "What will you have, DP or NP?" In Proceedings of the NELS 37, 101-114. Bošković, Željko. 2010. "On NPs and clauses." Ms., University of Connecticut. Bošković, Željko and Jon Gajewski. 2011. "Semantic correlates of the NP/DP parameter." In Proceedings of NELS 39. Gajewski, Jon. 2007. "Neg-raising and polarity." Linguistics \& Philosophy 30:289328. Horn, Laurence. 1978. "Remarks on neg-raising." Syntax and Semantics 9:129-220. Lahiri, Utpal. 1998. "Focus and negative polarity in Hindi." Natural Language Semantics 6:57-123. Lakoff, Robin. 1969. "A syntactic argument for negative transportation." In D. Binnick, G. Green, and J. Morgan, eds., Proceedings of Chicago Linguistic Society 5, 140-147. Zwarts, Frans. 1998. "Three types of polarity." In F. Hamm and E. W. Hinrichs, eds., Plurality and Quantification. Kluwer: 177-238. 